\title{
Application of an Improved Cloud Model and Distance Discrimination to Evaluate Slope Stability
}

\author{
Jiang Guo $(\mathbb{D}$, Jiachuang Wang $\mathbb{D}$, and Shihao Liu \\ School of Resources and Safety Engineering, Central South University, Changsha 410000, China \\ Correspondence should be addressed to Jiang Guo; guojiang@csu.edu.cn
}

Received 27 January 2019; Revised 9 April 2019; Accepted 18 April 2019; Published 4 August 2019

Academic Editor: Marek Lefik

Copyright (C) 2019 Jiang Guo et al. This is an open access article distributed under the Creative Commons Attribution License, which permits unrestricted use, distribution, and reproduction in any medium, provided the original work is properly cited.

\begin{abstract}
With the rapid development of China's economy, the construction of infrastructure has continuously improved. In the past few years, the construction of water conservancy projects has been constantly developing, and related geological disasters have become increasingly prominent. The stability of water conservancy slopes is related to whether water conservancy projects can be safely constructed and built to function safely and effectively, which has become a topic of increasing concern for geologists and related researchers. This paper selects the Jinping 1 Hydropower Station in Sichuan, China, for analysis. Four categories of evaluation factors (geological, engineering, environmental, and monitoring) and 24 subfactors (17 quantitative indicators and 7 qualitative indicators) are selected to ascertain the risk of the slope more accurately. By investigating the deficiencies of the traditional cloud model, the related concepts and computational models of a finite-area cloud model are proposed. By obtaining the characteristic parameters, the degrees of membership of the measurement samples belonging to different risk levels are further obtained. The weights of the indicators determined by the cloud processor and the weighted distance discriminant method are used to determine the final weights and achieve a final classification of the slope stability level. The research results demonstrate that the weighted distance discriminant algorithm combined with the improved finite-interval cloud model can consider the comprehensive information of each evaluation index and the degrees of mutual influence between the indicators, making the evaluation results more objective. Moreover, the proposed approach can quickly and accurately classify slope stability and deliver a prediction of the safety, thereby providing new ideas for evaluating the stability of slopes.
\end{abstract}

\section{Introduction}

The coincident improvements and construction of infrastructure and human engineering activities have greatly affected the geological environment, resulting in frequent slope failure disasters $[1,2]$. In recent years, the scale of facilities such as roads, dams, railways, and underground tunnels has become increasingly broad. Hydropower stations are major projects for the benefit of the people, and their safety is also related to the personal and property safety of the surrounding people. However, dam abutments have complex geological structures, and the abutment dam slope is an important factor in resisting external forces to bear the load transmitted from a dam. Consequently, the slope stability has become an important factor of the construction process, and the control of the slope stability also affects the key to the success of the project $[3,4]$. The instability mode of the slope has also recently received an increasing amount of attention.
The slope stability constitutes a systematic uncertainty that affects and threatens the safety of both human life and property. Slope stability analysis has become a key task in mining and geotechnical engineering [5]. Due to the randomness and complexity of the geological structure of a dam slope, it is very different from a soil slope. Therefore, geologists and related researchers in the fields of design and research are investigating slope stability in engineering construction projects with increasingly greater interest [6].

The main research object of initial landslide stability analyses was the soil; such analyses were based mainly on material mechanics, homogeneous elasticity, and elastoplastic theory. Subsequently, scholars focused on evaluation methods applicable to the stability of not only soil slopes but also rock slopes [7]. Accordingly, analyses and investigations of the factors affecting slope stability were performed, and the stability and types of slopes were classified. 
Three research methods are commonly employed to evaluate slope stability: the qualitative analysis method, the quantitative analysis method, and the uncertainty analysis method [8].

(a) Qualitative Analysis Method. Qualitative analysis is utilized mainly to conduct on-the-spot investigations and field investigations of the actual engineering geology and subsequently to determine the factors affecting slope stability. Through an analysis of the mechanical mechanisms of the instability and the failure mode, the evolution of both the slope body and the damage can be understood. Through qualitative analysis, it is possible to understand whether a slope is safe and the possible evolutionary characteristics of the slope. In addition, it is possible to comprehensively consider the factors that influence the slope stability. Examples of qualitative evaluations include analyses of the geological history, the engineering analogy method, and the graphical method, in addition to slope stability analysis databases and expert systems [9-11].

(b) Quantitative Analysis Method. Quantitative analysis is based on the mechanical properties of the slope body in consideration of various loads on the slope body, after which an appropriate mechanical model is selected for the analysis. Then, the appropriate parameters are used to quantitatively calculate slope stability. Finally, the calculation results are obtained by numerical simulation. Specific quantitative methods include the limit equilibrium method and numerical simulation method. The limit equilibrium method is relatively mature, and it is simple to meet the requirements of engineering applications using this approach. In contrast, due to the realization of geotechnical constitutive relationships, the numerical simulation method [12-14] is not sufficiently mature, which limits the reliability of its calculation results. Therefore, further research is needed.

(c) Uncertainty Analysis Method. Uncertainty is the main characteristic of most engineering problems, such as hydropower stations, and uncertainty is the characteristic of the evaluation method and the most prominent feature [15]. The use of measured natural data for slope stability evaluation is indeed full of uncertainty. The basic characteristics of uncertainty are the randomness and ambiguity discussed in probability theory and fuzzy mathematics, respectively. Slope rock and soil is an extremely complex geological medium, and its long-term geological action makes it one of the most complex materials in nature. Because its mechanical characteristic parameters, structural surface distribution law, and engineering geology are all complex and variable, the uncertainty of its evaluation mainly comes from the following three aspects: (1) the inherent heterogeneity of the rock and soil itself, (2) errors introduced by engineering parameter measurement and sampling, and (3) uncertainty caused by inaccurate models. Based on the characteristics of slope stability evaluation problems, many scholars have proposed many methods to improve their accuracy in the past few decades.
Since the 1990s, with the continuous development and augmentation of slope stability analysis theory, research regarding the evaluation of slope stability has gradually evolved from qualitative to quantitative research and from deterministic to uncertainty research $[16,17]$. Since a slope essentially represents an extremely complex and variable system, the factors affecting slope stability are random, fuzzy, and uncertain. Therefore, the slope uncertainty can be effectively treated by an appropriate uncertainty analysis method. Hence, academic experts and scholars have proposed different theories based on this uncertainty to explore slope stability. Examples of uncertainty analysis methods include reliability analysis methods [18], fuzzy theory evaluation methods [19-21], grey system evaluation methods [22], neural network evaluation methods [23, 24], genetic algorithms [25, 26], and the analytic hierarchy process (AHP) [27].

For example, S. Song et al. [28] used the cusp catastrophe model to consider the correlation of an evaluation index through the catastrophe progression method and analysed the internal mechanism of a landslide system. Q. Huang et al. [29] combined matter-element theory with the correlation function and improved the extended slope stability evaluation model. X. Dai et al. [30] and C. Yan [31] constructed the edge of the weighted distance discriminant model for evaluating the slope stability; this method compensates for the shortcomings of the importance of using the magnitude distance method to ignore indicators. In addition, J. Zhang et al. [32] and F. Yan [33] combined the basic concepts of cloud models according to the characteristics of the different stability levels of indicators and proposed a cloud model evaluation method for the stability of a rock slope. Furthermore, J. Zhao et al. [34] proposed a cloud model evaluation model based on the improved entropy weighting method considering comprehensive information regarding actual evaluation indicators. All these theories and models have improved the system for evaluating slope stability to a certain extent; through them, a theoretical basis for the working safety of slopes has been proposed.

However, due to the complexity of the factors affecting the stability of slopes, it is still difficult to overcome the defects inherent in the abovementioned theories. When evaluating actual working conditions, deviations from the actual situation are still evident. For instance, the fuzzy mathematical model of the cusp catastrophe model does not consider the weight of an index; rather, it measures only the relative importance of the index and is thus subjective. Moreover, the extension model still adopts a subjective assignment, and the method of weighting ignores some important constraints during the calculation process. In addition, the coupled neural network algorithm is computationally complex. Meanwhile, the sample obtained using this algorithm is not representative, and the fitting speed is difficult to control. Additionally, the normal cloud model ignores the correlations among the evaluation indicators, and the distribution of indicators is not completely normal. 
Based on the existing limitations of the research methods discussed above, this paper cites a finite-area cloud model as an improved cloud model that obeys a uniform distribution in combination with the actual evaluation indicators. The cloud model discussed herein is a conceptual model for addressing fuzzy problems proposed by D. Li et al. [35, 36], who addressed the ambiguity and randomness of data from a membership perspective. This cloud model has been applied to various engineering problems, such as the prediction of rock burst $[37,38]$, the stability analysis of surrounding rock [39], the quality classification of rock masses, and the evaluation of the spontaneous combustion tendency of ore. This model has also been widely used in military fields and has achieved good results for power grid performance, agricultural production, water quality assessment, and other areas [40-47]. However, the cloud model exhibits deficiencies when addressing unilateral issues. When the traditional cloud model is in a unilateral interval, that is, when it is in the interval of either $[0, C]$ or $[C, \infty]$, the index distribution of the edge is still the same as that of the traditional normal distribution. Thus, the simulation results under this theory often demonstrate a large deviation from the actual situation; therefore, a cloud model with a finite interval is introduced. The weighted distance discriminant algorithm $[48,49]$, which considers the degree of mutual influence between the levels to enhance the accuracy of the calculation results, is used to calculate the index weights. Finally, the application of this mathematical model to an evaluation of the slope of a hydropower station in China verifies the effectiveness of the proposed slope stability analysis technique [6].

\section{Methodology}

2.1. Basic Concept of the Cloud. A cloud model can be defined as a fuzzy model transformed by an uncertainty relationship represented by three mathematical descriptive symbols. Cloud theory forms the basis of generating a cloud model [35]. The normal cloud model describes qualitative concepts through parameter symbols of different features. Although the traditional cloud model can describe the uncertainty and randomness between evaluation indicators, it fundamentally assumes that the indicators tend to be normally distributed; in reality, however, the evaluation indicators do not completely obey a normal distribution and are limited. Rather, the interval obeys a near-normal distribution, and thus it is difficult to correctly describe the difference between the characteristics of the simulated object and the actual situation by using the traditional normal cloud model. According to the same principle, an already-determined index $x_{0}$ may be adjacent to but not on the actual level at which it is really located. Thus, the original infinite interval is converted into a finite interval, and the modified cloud model is converted into a finite interval.

Let $U$ be a quantitative set of exact numerical representations [35], where $U=\{x\}$ and $c$ are qualitative concepts on $U$. If there are arbitrary quantitative elements and $x$ has a stable tendency, a random number $\mu(\mathrm{x})=(0,1)$ is a random implementation of the qualitative concept $C$ among them:

$$
\mu: U \longrightarrow[0,1], \quad \forall x \in U, x \longrightarrow \mu(x)
$$

Then, the distribution of $x$ on the set $U$ is called a cloud, and each point $(x, \mu(x))$ is called a cloud drop.

2.2. Digital Features. According to the previous basic concept, the cloud model concept is expressed mainly by three basic digital features, namely, the expectation $E_{x}$, the entropy $E_{n}$, and the super entropy $H_{e}[37,50]$. The expectation $E_{x}$ represents the intermediate position of the qualitative concept, which is the central value of the universe. In a geometric sense, the random value corresponding to the highest point of an image determines the position of the cloud droplet distribution. The entropy $E_{n}$ is characterized in the domain interval. The value range of the cloud droplets expressed by this concept reflects the ambiguity and randomness of the basic concept. The value of $E_{n}$ also determines the degree of chaos among the cloud droplets. The larger the width of a cloud map is, the larger the value range of the cloud droplets. Accordingly, as the qualitative concept becomes more blurred, the cloud droplets become more discrete, and vice versa. The super entropy $H_{e}$, which is the entropy of the entropy, indicates the uncertainty in the entropy. In a cloud image, $H_{e}$ usually indicates the thickness of the cloud. The larger the super entropy is, the thicker the cloud.

According to the distribution of the risk level, a magnitude interval such as $\left[C_{\min }^{k}, \infty\right]$ or sum $\left[0, C_{\max }^{k}\right]$ exists, and the index variable at this time no longer obeys the traditional cloud model distribution. Therefore, the edge blur $\mu(x)$ interval should be transformed into a uniform distribution with a certainty degree of 1 ; this interval is usually described by a half-litre trapezoidal cloud and a half-falling trapezoidal cloud [30]. It is easy to prove that the finite-interval $[\gamma]$-order normal density function has the same variance and expectation as the infinite-interval $[\gamma]$ order normal distribution density function, and the following equations used to calculate the corresponding set of cloud characteristic parameters can be obtained:

$$
\begin{aligned}
E_{x}^{k} & =\frac{C_{\max }^{k}+C_{\min }^{k}}{2} \\
E_{n}^{k} & =\frac{C_{\max }^{k}-C_{\min }^{k}}{2 \sqrt{[\gamma]+3}} \\
H_{e}^{k} & =\lambda E_{n}^{k}
\end{aligned}
$$

In the above formulas, $C_{k}$ is the half-length of the $K$ th level; $C_{\max }^{k}$ and $C_{\min }^{k}$ are the upper and lower bounds, respectively, of the rank interval; $[\gamma]$ is the order of the normal density function in the finite interval taking the largest integer of $\gamma$; and $\lambda$ is an empirical value (taken in this paper to be 0.01 ) that can be adjusted according to the fuzzy degree of the index variable. Let the indicator limit value belong to the same level as two levels of 0.5 . The algorithm of the order of its normal distribution function is recorded as follows [51]:

$$
[\gamma]=\frac{\lg 0.5}{\lg \left\{1-\left[2\left(C^{k}-E_{x}^{k}\right) / \xi_{k}\right]^{2}\right\}}
$$


In the above formula, $\xi_{k}$ is the endpoint of the level interval $K$. When the evaluation indicator type is larger, the indicator value and the level interval increase. Then, the lengths $\xi_{k}^{l}$ and $\xi_{k}^{r}$ of the left- and right-hand intervals of level $K$ are as follows:

$$
\begin{aligned}
& \xi_{k}^{r}=C_{\max }^{k+1}-E_{x}^{k} ; \\
& \xi_{k}^{l}=E_{x}^{k}-C_{\min }^{k-1}
\end{aligned}
$$

Similarly, the larger the index value is, the smaller the level interval, and the lengths of the left- and right-hand intervals of level $K$ are as follows:

$$
\begin{aligned}
& \xi_{k}^{l}=E_{x}^{k}-C_{\min }^{k+1} ; \\
& \xi_{k}^{r}=C_{\max }^{k-1}-E_{x}^{k}
\end{aligned}
$$

2.3. Cloud Generator. The cloud generator is the key to utilizing the cloud model for purposes ranging from theoretical to practical applications [52]. Usually, the cloud generator includes both a forward cloud generator and a reverse cloud generator. A forward cloud generator $C G$ usually uses cloud characteristic parameters $N\left(E_{x}, E_{n}, H_{e}\right)$ to generate cloud droplets $P\left(x_{i}, \mu_{i}\right)(i=1,2,3 \ldots n)$. Usually, this process is a transformation from a qualitative analysis to a quantitative calculation. In contrast, a reverse cloud generator $C G^{-1}$ uses the three cloud characteristic parameters of the cloud drop graph to transform them into qualitative concepts. Therefore, the combination of these two cloud generators can be utilized to generate different types of cloud models using different qualitative concepts and quantitative calculations.

Using the above description, the digital features of the cloud are expressed as $x \sim\left(E_{x}, E_{n}, H_{e}\right)$. Combined with the index-level feature, the fitting can be performed by MATLAB programming with the help of the digital features and the number of cloud droplets $\mathrm{N}$ to be generated (this article takes $N=5000$ ). When the indicator is within the interval between the mean cloud values of the two edges, the mathematical conceptual model can be defined as follows: let $U$ be a quantitative set of exact numerical representations, $U=\{x\}$, where $C$ represents qualitative concepts on $U$. If there is any quantitative element $x$ and if $x$ has a stable tendency, the random number $\mu(x)=[0,1]$ is a stochastic implementation of the qualitative concept $C$. Here, if $x$ satisfies $x \sim\left(E_{x}, E_{n}^{\prime 2}\right)$, as follows from set pair theory, the same indicator can belong only to the adjacent level interval, and it cannot belong to the infinite level interval. Therefore, the infinite interval can be converted into a finite interval. Furthermore, the evaluation index $x$ can be transformed from a normal distribution over an infinite interval into a normal distribution over a finite interval. The certainty of $x$ in $C$ is satisfied as follows:

$$
\mu=\exp \left(\frac{-\left(x-E_{x}\right)^{2}}{2 E_{n}^{\prime 2}}\right)
$$

When the indicator is far from the expected value of $E x$, $x$ obeys a uniform distribution with a certainty degree of 1 .
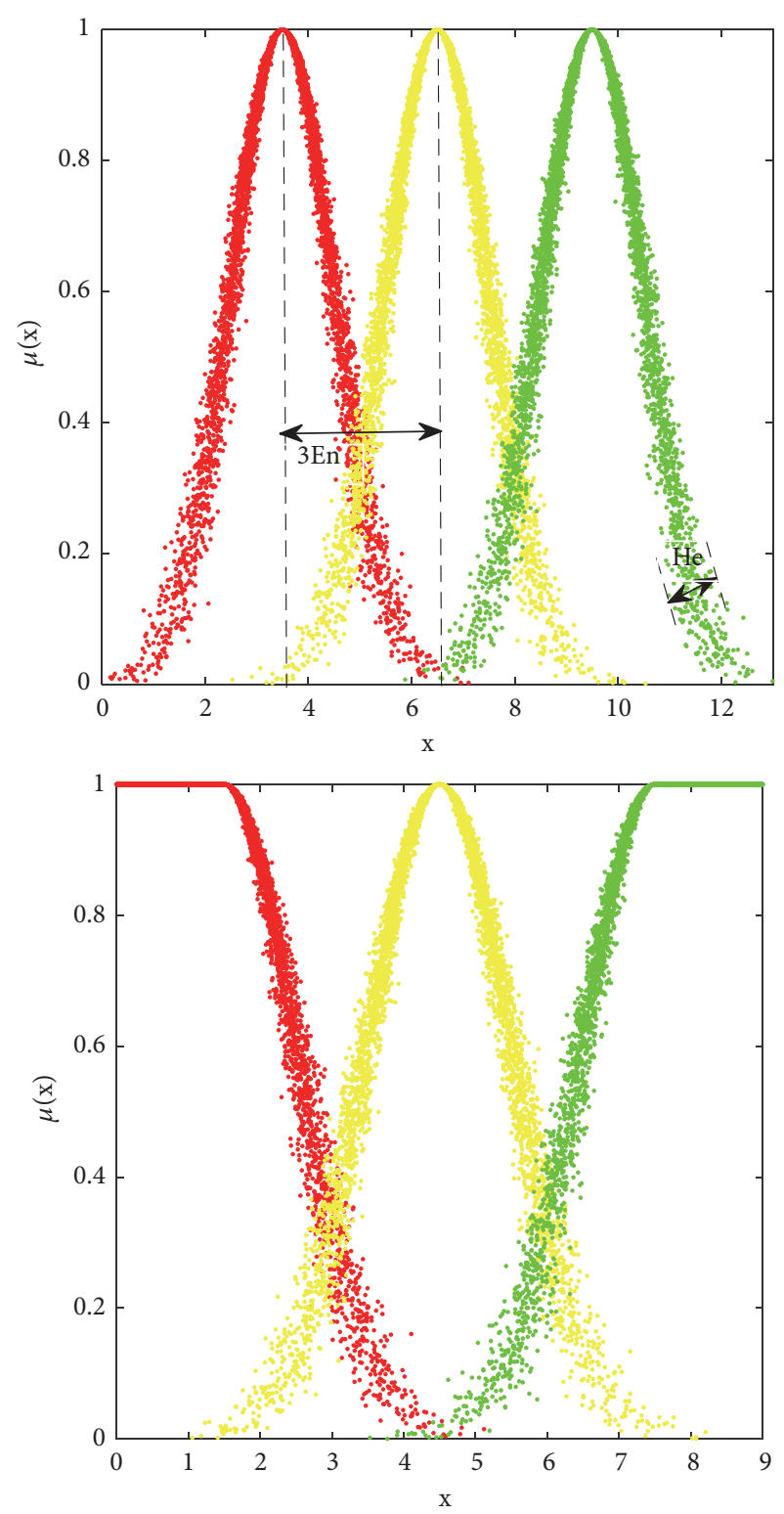

FIGURE 1: Traditional cloud model and finite-interval cloud model.

In summary, the distribution of $x$ obeys the following (in this article, $\left.k m_{\mathrm{ax}}=5\right)$ :

$$
\begin{aligned}
& \mu=1 \quad x \in\left[C_{\min }^{k_{\max }}, \infty\right) \cup\left(0, C_{\max }^{k_{\min }}\right] \\
& \mu=\exp \left(\frac{-\left(x-E_{x}\right)^{2}}{2 E_{n}^{\prime 2}}\right) \quad x \in \text { other interval }
\end{aligned}
$$

According to (9), we can see that when the indicator is far away from the expectation, then $x$ obeys a uniform distribution with a certainty degree of 1 .

As shown in Figure 1, the quantitative element $x$ in two diagrams represents the quantitative random number on the 
domain interval $U$, and $\mu(x)$ indicates that the quantitative element $x$ corresponds to the interval membership degree, which ranges from $0 \sim 1$. The horizontal coordinates represent the range of the selected evaluation indicators. In the first picture, the expectation of the adjacent two interval ranges is $E_{x}$, the distance between them is $3 E_{n}$, the longitudinal coordinate represents the membership degree, and the $x$ of the peak place corresponds to the $E_{x}$ point. In the cloud model parameters, $E_{n}$ represents the thickness of the curve, representing the physical meaning of the degree of confusion of the cloud droplets. The improved cloud model diagram indicates that when the quantitative element $x$ is in the edge interval (the artificially specified maximum and minimum levels), it can be determined that the quantitative element $x$ is subject to a uniform distribution at $E_{x}$ as the dividing point, at which point the interval membership degree is 1.

Using the forward cloud generator and the characteristic parameter values, the degrees of membership corresponding to different measured evaluation indexes can be further obtained. The specific algorithm and steps are as follows.

(1) Review the relevant literature in addition to specific engineering surveys and data to obtain measured data and further calculate the entropy $E_{n}$ and super entropy $H_{e}$. Because the super entropy is characterized by the thickness of the cloud, we can temporarily take $\lambda=0.01$.

(2) According to the improved formula, the cloud characteristic parameter can be obtained, as can the random number $E_{n}^{\prime} \sim N\left(E_{n}, H_{e}^{2}\right)$ of the normal distribution.

(3) According to the actual survey index $x$, in addition to (9) and using the specific grading standard of the hazard of the slope risk to obtain $E_{x}$, the hazard level membership degree of the measured index can be obtained in combination with the cloud droplet map.

The application of the improved forward normal cloud model to slope stability analysis is based on the following four reasons.

(1) The slope risk classification is full of uncertainty, and thus the cloud model is used to study the uncertainty in the concept of human cognition through three numerical characteristics: expectation, entropy, and super entropy.

(2) The normal cloud model is based on a normal distribution and is the most commonly used cloud model. It exhibits universality, and the expected curves of the cloud model with many qualitative concepts in the natural sciences approximately obey normal distributions. Following further improvement, the curve will become more subordinate to the actual situation.

(3) The cloud model is a two-way cognitive model of qualitative and quantitative conversions that is divided into positive clouds and reverse clouds. The slope risk classification constitutes a transformation from qualitative to quantitative research corresponding to the forward cloud model.

(4) The stability of a slope is a problem in which a variable is affected by multiple factors. The improved normal cloud model can treat each factor as a variable, enabling it to intuitively and quickly address the slope stability prediction problem; moreover, the improved model can reflect the extent to which different slopes belong to the same slope risk level.

\section{Finite-Area Cloud Model and Distance Discrimination for Building a Weighted Model}

3.1. Construction of the Slope Stability Evaluation System. The stability evaluation and analysis of a slope ultimately constitutes a fuzzy problem. The stability of a slope can be considered to characterize its safety factor. By analysing several articles [53-57] evaluating the stability of rock slope, we find the following: (1) The factors affecting the stability of rock slope are related to the geometry of the slope, the excavation process, and engineering support. (2) Its stability is related to stratum structure and rock lithology. (3) Among the many evaluation factors, its stability is related to the regional environment where the slope is located, such as the local rainfall and earthquakes. The stability coefficients of different working conditions can be represented by a unified function:

$$
F_{s}=g(X)=g(C, \varphi, H, \alpha \ldots)
$$

In the above function, $X$ represents all the evaluation factors that affect slope stability. For example, $C$ is the cohesive force of rock and soil, $\varphi$ denotes the internal friction angle of a rock mass, $H$ is the slope height, $\alpha$ is the slope angle, and $g(X)$ is the function used to calculate the stability quantitatively. Under actual working conditions, many influencing factors are ambiguous; thus, many qualitative factors are represented by fuzzy values and can be written as follows:

$$
\vec{F}_{s}=\overrightarrow{g(X)}=g(\vec{C}, \vec{\varphi}, H, \alpha \ldots)
$$

Slope stability is affected by its own complex characteristics and the available engineering technology. The most important factors include the geological features of the slope, the hydrological structure, and the external environment, which encompass human production activities, geological disasters, and precipitation. To date, no uniform standards to determine the stability of slopes have been presented in the academic or geological engineering circles. The current slope safety assessment method fails to integrate the complex rock mass stress, slope characteristics, rock properties, rock mass structure, natural factors, and human activities and other factors, so it is difficult to objectively and comprehensively evaluate the overall stability of the slope, especially the choice of the slope impact factors of hydropower stations; therefore, the choice of factors in this paper is mainly limited to hydropower projects involving rock slopes. According to established grading standards, the evaluation indicators should satisfy the five following principles: representativeness relevance, quantifiability, accessibility, and reservability. Therefore, for improving the accuracy of the evaluation, this paper selects the following evaluation indicators for analysis:

(a) Geological factors (P1): deformation modulus $\left(\mathrm{X}_{1-1}\right)$; integrity index of the rock mass $\left(\mathrm{X}_{1-2}\right)$; rock quality designation (RQD) $\left(\mathrm{X}_{1-3}\right)$; uniaxial compressive strength (UCS) $\left(\mathrm{X}_{1-4}\right)$; initial index $\left(\mathrm{X}_{1-5}\right)$; and condition of discontinuities $\left(\mathrm{X}_{1-6}\right)$.

(b) Engineering factors (P2): slope height $\left(\mathrm{X}_{2-1}\right)$; slope angle $\left(\mathrm{X}_{2-2}\right)$; reinforcements $\left(\mathrm{X}_{2-3}\right)$; drainage condition $\left(\mathrm{X}_{2-4}\right)$; 


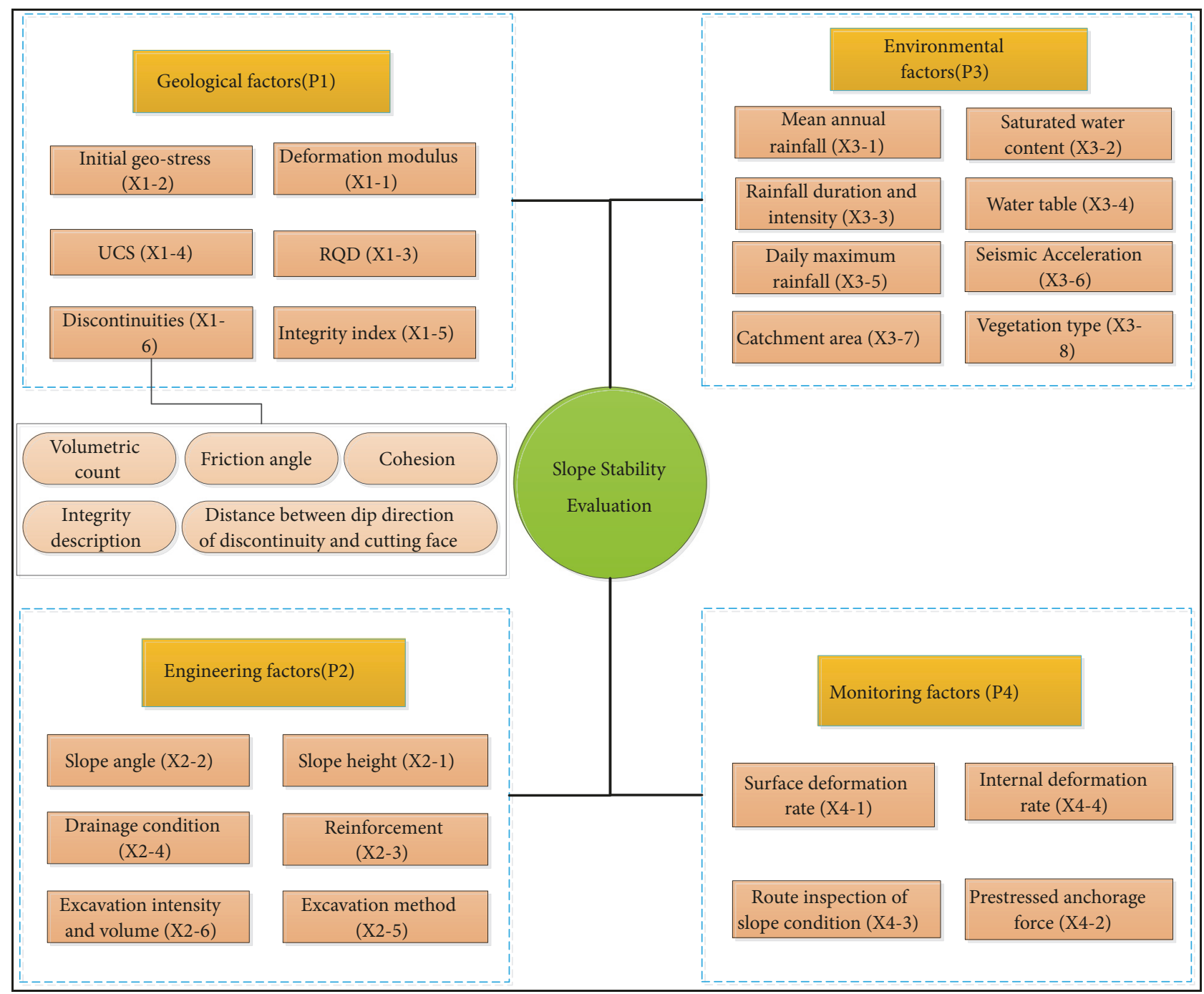

FIGURE 2: The comprehensive evaluation indicators.

excavation method $\left(\mathrm{X}_{2-5}\right)$; and excavation intensity and volume $\left(\mathrm{X}_{2-6}\right)$.

(c) Environmental factors (P3): mean annual precipitation $\left(\mathrm{X}_{3-1}\right)$; saturated water content of the slope $\left(\mathrm{X}_{3-2}\right)$; rainfall duration and intensity $\left(\mathrm{X}_{3-3}\right)$; water table $\left(\mathrm{X}_{3-4}\right)$; daily maximum rainfall $\left(\mathrm{X}_{3-5}\right)$; seismic acceleration $\left(\mathrm{X}_{3-6}\right)$; catchment area $\left(\mathrm{X}_{3-7}\right)$; and vegetation type $\left(\mathrm{X}_{3-8}\right)$.

(d) Monitoring factors (P4): surface deformation rate $\left(\mathrm{X}_{4-1}\right)$; prestressed anchorage force $\left(\mathrm{X}_{4-2}\right)$; internal deformation rate $\left(\mathrm{X}_{4-3}\right)$; and route inspection of the slope condition $\left(\mathrm{X}_{4-4}\right)$.

A comprehensive graph of the evaluation indicators is shown in Figure 2 [6].

According to the characteristics of the rock slope in an engineering project, the selection criteria for the evaluation indicators are selected in consideration of the systematic comprehensiveness, concise scientificity, relative independence, and flexible operability of the modelling process. Macrofactors should be selected while avoiding specific physical and mechanical properties. The indicators should be comprehensive, representative, and coordinated but also encompass the main influencing factors as much as possible; the greater the independence of the factors, the better the correlation. Moreover, the factors should be combined to avoid difficulties when selecting a fuzzy synthetic model.

3.2. Grading Criteria for Evaluation Indicators. Due to the randomness and ambiguity of the factors that affect the rock slope stability, stability changes both with the time and with the environment. The basis of the grading standard is usually related to the actual situation of the rock slope and the discontinuous geological conditions. In general, as a result of different engineering backgrounds, many potential factors will affect the actual working conditions. Consequently, the slope is divided into five grades, namely, completely stable (I), stable (II), partially stable (III), unstable (IV), and completely unstable (V), according to the classification criteria of the engineering rock mass, thereby forming a single-factor slope stability evaluation index according to different classification level standards. The specific descriptions of the different levels 
are listed in Table $1[21,58]$, and the specific parameters are reported in Table $2[59,60]$.

3.3. Evaluation Factor Weight Calculation. For any evaluation method, especially for the target evaluation index, considering the weights of numerous different evaluation factors is usually required. These so-called weights refer to the relative importance of the evaluation factors that affect the problem in the evaluation process. Descriptions of the weights can be either qualitative or quantitative. However, the qualitative description of a weight is subjective, and thus the weight of an indicator in an actual process is usually expressed by a specific algorithm. Commonly used methods for calculating index weights include the AHP $[61,62]$, the entropy weight method $[63,64]$, and the RS method $[65,66]$, among others [67-70]. However, most of these methods are subjective, and thus it is difficult to obtain objective and accurate results. In addition, while the entropy weight method is a commonly used objective weighting technique, this approach usually considers only the amount of information regarding the indicators; in other words, the correlations among the evaluation indicators are not considered. Accordingly, this paper adopts another objective weighting method known as the weighted distance discriminant method. The specific steps of this method are as follows [30]:

Step 1. Solution of the normal membership degree (determination degree): according to the measured value corresponding to each index $E_{i}$ of the evaluation object, refer to the method of improving the characteristic parameters of the cloud model; then, the membership degree of the corresponding risk level $K$ to which each evaluation index belongs can be obtained.

Step 2. Calculating the distance between two indicators: assuming that $m_{k}^{i}$ and $m_{k}^{j}$ are the basic probability distribution functions of the two levels corresponding to the two indicators $E_{i}$ and $E_{\mathrm{j}}$, respectively, the distance between the two indicators can be expressed as follows:

$$
D\left(E_{i}, E_{j}\right)=\sqrt{\frac{1}{2}\left(\left\|m_{i}^{k}\right\|^{2}+\left\|m_{j}^{k}\right\|^{2}-2\left\langle m_{i}^{k}, m_{j}^{k}\right\rangle\right)}
$$

In this formula, $\left\|m_{j}^{k}\right\|^{2}=\left\langle m_{j}^{k}, m_{j}^{k}\right\rangle,\left\langle m_{i}^{k}, m_{j}^{k}\right\rangle$ is the inner product of two vectors. The level of the hazard corresponding to the evaluation object selected in this paper is 5 ; thus, $K=5$, and the distance between the two indicators $D\left(E_{i}, E_{j}\right)$ can be obtained from the above formula.

Step 3. Calculating the similarity: according to the distance between the two indicators $E_{i}$ and $E_{j}$ obtained with the previous formula, the similarity $S\left(E_{i}, E_{j}\right)$ between these two indicators can be obtained as follows:

$$
S\left(E_{i}, E_{j}\right)=1-D\left(E_{i}, E_{j}\right)
$$

Step 4. Calculating the support level of the indicators: according to the above calculation formula, the smaller the distance between the indicators is, the greater the similarity and the better the consistency between them. Then, the support level of the calculated indicators is as follows:

$$
\sup \left(E_{i}\right)=\sum_{j=i, j \neq i}^{n} S\left(E_{i}, E_{j}\right) \quad i=1,2,3 \ldots n
$$

Step 5. Calculating the weights of the evaluation indicators: normalization can further yield the credibility $\omega\left(E_{i}\right)$ of each indicator $E_{i}$ (the weights of the different evaluation factors):

$$
\omega\left(E_{i}\right)=\frac{\sup \left(E_{i}\right)}{\sum_{i=1}^{n} \sup \left(E_{i}\right)} \quad i=1,2,3 \ldots n
$$

3.4. Determination of Comprehensive Weights. After the expansion and calculation of the above steps, we can conclude that the measured data $x$ of different evaluation indicators belongs to a specific certainty degree in the cloud $\mu(x)$. Then, we can employ the weighted distance discriminant method to calculate the weights of the different evaluation indicators using the final comprehensive determination formula:

$$
\mu_{k}=\sum_{j=1}^{m} \omega\left(E_{j}\right) \cdot \mu_{k, j}
$$

In the above formula, $\mu_{k, j}$ is the certainty of the measured value of the $j$ th indicator of the sample, and $\omega\left(E_{j}\right)$ is the weight of the $j$ th evaluation index of the sample.

According to the final comprehensive determination and the principle of maximum membership, we can determine the membership level of the sample as follows:

$$
L=\max \left(\mu_{1}, \mu_{2}, \mu_{3} \ldots \mu_{k}\right)
$$

3.5. Framework for Calculating and Evaluating Slope Stability. (a) According to research concerning slope stability analysis performed by many scholars and geologists, a risk classification standard is established for landslide evaluation indicators.

(b) The cloud characteristic parameters of the classification index are determined, and the cloud generator is used to draw the cloud droplet map to generate a cloud model.

(c) The degree of certainty corresponding to each indicator is calculated based on the measured data of the sample.

(d) The weight of each evaluation index is calculated by using the algorithm of the improved weighted distance discriminant method.

(e) The comprehensive weight values are calculated, and the slope hazard level is determined according to the principle of maximum membership.

The specific operation flow chart is shown in Figure 3.

\section{Engineering Applications}

4.1. Background Information of the Jinping 1 Hydropower Station. The Jinping 1 Hydropower Station $[6,71,72]$, a massive controlled-reservoir cascade hydropower station situated in the lower reaches of the Yalong River (Kala to Jiangkou section), is in Yanyuan County and Muli County, Liangshan 
TABLE 1: Slope stability grades and empirical descriptions.

\begin{tabular}{lccccc}
\hline Rank & Description & Stability & Safety & Failures & Treatment \\
\hline I & Very favourable & Completely stable & Completely safe & None & None \\
II & Favourable & Stable & Safe & Some blocks & Occasional \\
III & Fair & Partially stable & Moderately safe & Some joints or many wedges & Systematic \\
IV & Unfavourable & Unstable & Unsafe & Planar or big wedges & Important/corrective \\
V & Very unfavourable & Completely unstable & Dangerous & Big planar, soil-like failures & Re-excavation \\
\hline
\end{tabular}

TABLE 2: Single-factor slope stability evaluation index.

\begin{tabular}{|c|c|c|c|c|c|}
\hline \multirow{2}{*}{ Rating factor } & \multicolumn{5}{|c|}{ Ranking grade } \\
\hline & I & II & III & IV & $\mathrm{V}$ \\
\hline \multicolumn{6}{|c|}{ Geological factors (P1) } \\
\hline Deformation modulus $\left(\mathrm{X}_{1-1}\right)(\mathrm{GPa})$ & $33.0-50.0$ & $20.0-33.0$ & $6.0-20.0$ & $1.3-6.0$ & $0-1.3$ \\
\hline Integrity index $\left(\mathrm{X}_{1-2}\right)$ & $0.75-1$ & $0.55-0.75$ & $0.35-0.55$ & $0.15-0.35$ & $0-0.15$ \\
\hline $\operatorname{RQD}\left(\mathrm{X}_{1-3}\right)$ & $90-100$ & $75-90$ & $50-75$ & $25-50$ & $0-25$ \\
\hline $\operatorname{UCS}\left(\mathrm{X}_{1-4}\right)(\mathrm{MPa})$ & $>250$ & $100-250$ & $50-100$ & $25-50$ & $0-25$ \\
\hline Initial geo-stress $\left(\mathrm{X}_{1-5}\right)(\mathrm{MPa})$ & $0-2$ & $2-8$ & $8-14$ & $14-20$ & $20-25$ \\
\hline \multicolumn{6}{|l|}{ Discontinuities $\left(\mathrm{X}_{1-6}\right)$} \\
\hline Cohesion $\left(\mathrm{X}_{1-6-1}\right)(\mathrm{MPa})$ & $0.22-0.32$ & $0.12-0.22$ & $0.08-0.12$ & $0.05-0.08$ & $0-0.05$ \\
\hline Friction angle $\left(\mathrm{X}_{1-6-2}\right)\left(^{\circ}\right)$ & $37-45$ & $29-37$ & $21-29$ & $13-21$ & $0-13$ \\
\hline Volumetric count $\left(\mathrm{X}_{1-6-3}\right)$ & $0-3$ & $3-10$ & $10-20$ & $20-35$ & $>35$ \\
\hline Integrity description $\left(\mathrm{X}_{1-6-4}\right)$ & Very good & Good & Moderate & Bad & Very bad \\
\hline $\begin{array}{l}\text { Distance between the dip direction of the } \\
\text { discontinuity and cutting face }\left(\mathrm{X}_{1-6-5}\right)\end{array}$ & Very far & Far & Fair & Close & Very close \\
\hline \multicolumn{6}{|c|}{ Engineering factors (P2) } \\
\hline Slope height $\left(\mathrm{X}_{2-1}\right)(\mathrm{m})$ & $0-30$ & $30-45$ & $45-60$ & $60-80$ & $80-100$ \\
\hline Slope angle $\left(\mathrm{X}_{2-2}\right)\left(^{\circ}\right)$ & $0-20$ & $20-35$ & $35-45$ & $45-60$ & $60-80$ \\
\hline Reinforcements $\left(\mathrm{X}_{2-3}\right)$ & Surplus & Sufficient & Fair & Insufficient & Barely \\
\hline Drainage condition $\left(\mathrm{X}_{2-4}\right)$ & Very favourable & Favourable & Fair & Unfavourable & $\begin{array}{c}\text { Very } \\
\text { unfavourable }\end{array}$ \\
\hline Excavation method $\left(\mathrm{X}_{2-5}\right)$ & No excavation & Manual & Mixed & Explosion & Large explosion \\
\hline Excavation intensity and volume $\left(\mathrm{X}_{2-6}\right)$ & Very favourable & Favourable & Fair & Unfavourable & $\begin{array}{c}\text { Very } \\
\text { unfavourable }\end{array}$ \\
\hline \multicolumn{6}{|c|}{ Environmental factors (P3) } \\
\hline Mean annual precipitation $\left(\mathrm{X}_{3-1}\right)(\mathrm{mm})$ & $0-600$ & $600-800$ & $800-1,100$ & $1,100-1,500$ & $1,500-2,000$ \\
\hline $\begin{array}{l}\text { Saturated water content of the slope }\left(\mathrm{X}_{3-2}\right) \\
(\%)\end{array}$ & $0-20$ & $20-40$ & $40-55$ & $55-75$ & $75-100$ \\
\hline Rainfall duration and intensity $\left(\mathrm{X}_{3-3}\right)$ & Very favourable & Favourable & Fair & Unfavourable & $\begin{array}{c}\text { Very } \\
\text { unfavourable }\end{array}$ \\
\hline Water table $\left(\mathrm{X}_{3-4}\right)$ & Very low & Low & Fair & High & Very high \\
\hline Daily maximum rainfall $\left(\mathrm{X}_{3-5}\right)(\mathrm{mm})$ & $0-25$ & $25-50$ & $50-70$ & $70-100$ & $100-150$ \\
\hline Seismic acceleration $\left(\mathrm{X}_{3-6}\right)(\mathrm{g})$ & $0-0.05$ & $0.05-0.1$ & $0.1-0.15$ & $0.15-0.20$ & $0.20-0.40$ \\
\hline Catchment area $\left(\mathrm{X}_{3-7}\right)$ & Very favourable & Favourable & Fair & Unfavourable & $\begin{array}{c}\text { Very } \\
\text { unfavourable }\end{array}$ \\
\hline Vegetation type $\left(\mathrm{X}_{3-8}\right)$ & Very favourable & Favourable & Fair & Unfavourable & $\begin{array}{c}\text { Very } \\
\text { unfavourable }\end{array}$ \\
\hline \multicolumn{6}{|c|}{ Monitoring factors (P4) } \\
\hline Surface deformation rate $\left(\mathrm{X}_{4-1}\right)(\mathrm{mm} / \mathrm{m})$ & $0-2$ & $2-3$ & $3-5$ & $5-8$ & $8-10$ \\
\hline Pre-stressed anchorage force $\left(\mathrm{X}_{4-2}\right)(\%)$ & $0-8$ & $8-15$ & $15-20$ & $20-25$ & $25-30$ \\
\hline Internal deformation rate $\left(\mathrm{X}_{4-3}\right)(\mathrm{mm} / \mathrm{m})$ & $0-0.3$ & $0.3-0.8$ & $0.8-1.5$ & $1.5-2$ & $2-3$ \\
\hline Route inspection of slope condition $\left(\mathrm{X}_{4-4}\right)$ & Very good & Good & Moderate & $\mathrm{Bad}$ & Very bad \\
\hline
\end{tabular}




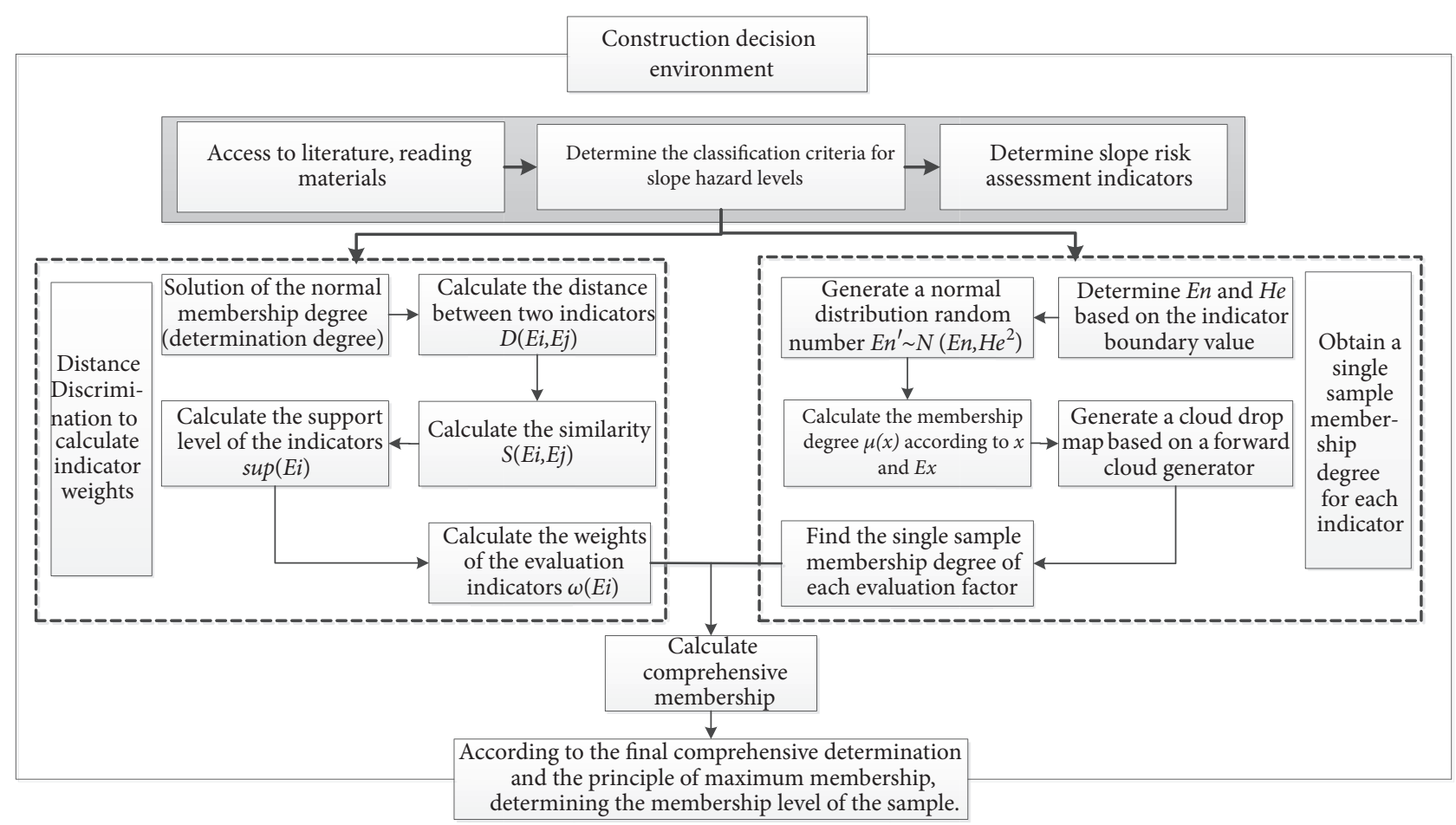

FIGURE 3: Framework for calculating and evaluating slope stability.

Yi Autonomous Prefecture, Sichuan Province. The stream and the valleys along the path of the Yalong River are deep, and the river presents many rapids; thus, navigation is not possible. The land along the river is sparsely populated, and cultivated land is scattered along the stream. There are no important towns or industrial mining enterprises. The main task of the development of the hydropower project is power generation, although it is also expected to serve as a flood storage reservoir during the flooding season, thereby reducing the flood control burden on the middle and lower reaches of the Yangtze River. The 305-m high hub building of the Jinping 1 Hydropower Station is the world's tallest arch dam. The hub area, which is affected by complex topographic and geological conditions, is a V-shaped canyon with steep slopes and microgeomorphic features. The geological structures in the valley are both soft and hard, the topography dips in opposite directions, and the upper part of the hub area is open and narrow. The stream of the Yalong River rapidly downcuts, and the region is pervaded by a high-stress background; thus, deep cracks are developed along the deep slope of the left bank. Through scientific research tracking, safety monitoring feedback, dynamic design technology, and construction technology research, the slope can be smoothly designed and constructed, and it can be controlled safely and effectively. To explore the actual degree of danger associated with the arch dam, this paper selects the improved cloud model and weighted distance discriminant method to ascertain the hazard of the arch dam.

The measured values of the indicators are listed in Table 3. For some indicators that can be only qualitatively described, we can assume that the probabilities that these evaluation factors are qualitatively described within these intervals are subject to different levels since the range of weights is between 0 and 1 . We can then assign values according to the classification method; that is, we can divide the interval $[0,1]$ into five equal subintervals: $[0,0.2],[0.2,0.4],[0.4,0.6],[0.6,0.8]$, and $[0.8,1.0]$. Then, we can assign values to the qualitative indicators according to their quantitative descriptions, whereas the values of the remaining quantitative indicators can be obtained through actual survey and research data [6].

4.2. Standardized Processing of Measured Sample Data. To eliminate the dimensional differences between different indicators, it is necessary to normalize the sample data. In this paper, the Z-score method is used to normalize the data samples. The specific formula can be expressed as follows:

$$
x^{*}=\frac{x-\mu}{\sigma}
$$

where $\mu$ is the mean of all sample data and $\sigma$ is the standard deviation of all sample data; they are defined as follows:

$$
\begin{aligned}
\mu & =\frac{1}{m} \sum_{i=1}^{m} x_{i} \\
\sigma & =\sqrt{\frac{1}{m-1} \sum_{i=1}^{m}\left(x_{i}-\mu\right)}
\end{aligned}
$$

4.3. Generation of the Cloud Droplet Graph. To verify the reliability and effectiveness of the proposed method, this 
TABLE 3: Actual evaluation values of different evaluation indicators.

\begin{tabular}{lccc}
\hline Evaluation factor & Original & Evaluation factor & Original \\
\hline Deformation modulus $\left(\mathrm{X}_{1-1}\right)$ & $1.9 \mathrm{GPa}$ & Reinforcements $\left(\mathrm{X}_{2-3}\right)$ & 0.70 \\
Integrity index $\left(\mathrm{X}_{1-2}\right)$ & 0.72 & Drainage effect $\left(\mathrm{X}_{2-4}\right)$ & 0.75 \\
$\mathrm{RQD}\left(\mathrm{X}_{1-3}\right)$ & $85 \%$ & Mean annual precipitation $\left(\mathrm{X}_{3-1}\right)$ & $607 \mathrm{~mm}$ \\
$\mathrm{UCS}\left(\mathrm{X}_{1-4}\right)$ & $105 \mathrm{MPa}$ & Water content $\left(\mathrm{X}_{3-2}\right)$ & $13 \%$ \\
Initial geo-stress $\left(\mathrm{X}_{1-5}\right)$ & $21.49 \mathrm{MPa}$ & Daily maximum rainfall $\left(\mathrm{X}_{3-5}\right)$ & $49.2 \mathrm{~mm}$ \\
Cohesion $\left(\mathrm{X}_{1-6-1}\right)$ & $0.02 \mathrm{MPa}$ & Seismic acceleration $\left(\mathrm{X}_{3-6}\right)$ & $0.1 \mathrm{~g}$ \\
Friction angle $\left(\mathrm{X}_{1-6-2}\right)$ & $16.7^{\circ}$ & Surface deformation rate $\left(\mathrm{X}_{4-1}\right)$ & $1.89 \mathrm{~mm} / \mathrm{m}$ \\
Volumetric count $\left(\mathrm{X}_{1-6-3}\right)$ & $17 / \mathrm{m}^{3}$ & Pre-stressed anchorage force $\left(\mathrm{X}_{4-2}\right)$ & $8.73 \%$ \\
Integrity description $\left(\mathrm{X}_{1-6-4}\right)$ & 0.60 & Internal deformation rate $\left(\mathrm{X}_{4-3}\right)$ & $0.27 \mathrm{~mm} / \mathrm{m}$ \\
Slope height $\left(\mathrm{X}_{2-1}\right)$ & $110 \mathrm{~m}$ & Route inspection $\left(\mathrm{X}_{4-4}\right)$ & 0.75 \\
Slope angle $\left(\mathrm{X}_{2-2}\right)$ & $50^{\circ}$ & & \\
\hline
\end{tabular}

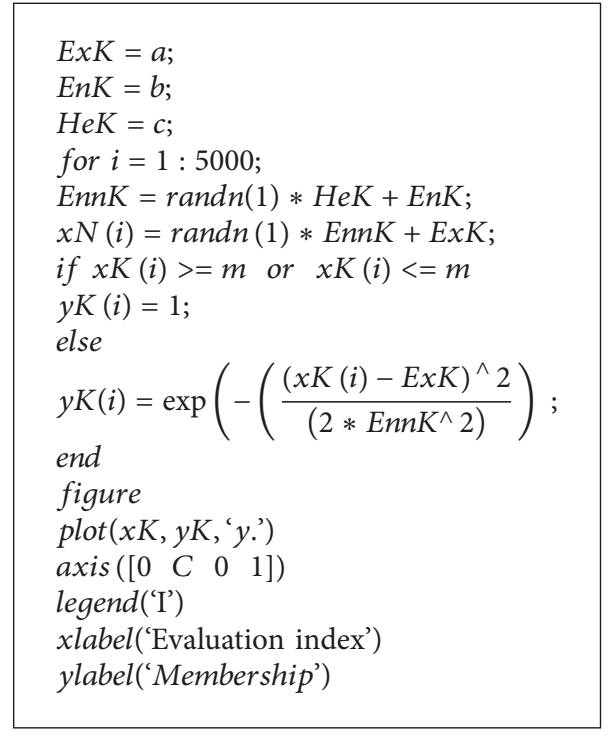

Algorithm 1

paper selects the Jinping 1 Hydropower Station as the research background and uses its indicator system and measured data for a verification and comparative analysis. According to the finite-area cloud model and grading standards, the cloud feature parameters are determined by using (2)-(7). The generated cloud droplet map is shown in Figure 4, in which the abscissa indicates the evaluation indicator and the ordinate indicates the degree of certainty determined by the evaluation indicators with different values, that is, the degree of membership. Because the specific values of some qualitatively described indicators in this article are obtained according to the classification method and by assignment, only the quantitative descriptions of those indicators and the quantitative evaluation factors with specific survey values are described by the cloud map in Figure 4. According to the cloud characteristic parameters and the forward cloud generator, a cloud droplet graph is generated. The specific algorithm is as shown in Algorithm 1.

4.4. Determination of the Weights of the Evaluation Indicators. According to the cloud droplet graph and the membership formula generated in Figure 3, the measured values of the samples evidently belong to different hazard levels.

$$
R=\left\{\begin{array}{cccccc}
T & \mathrm{I} & \mathrm{II} & \mathrm{III} & \mathrm{IV} & \mathrm{V} \\
X_{1-1} & 0 & 0 & 0.19 & 0.71 & 0.1 \\
X_{1-2} & 0.32 & 0.67 & 0.01 & 0 & 0 \\
X_{1-3} & 0.05 & 0.85 & 0.1 & 0 & 0 \\
X_{1-4} & 0 & 0.60 & 0.40 & 0 & 0 \\
X_{1-5} & 0 & 0 & 0 & 0.19 & 0.81 \\
X_{16-1} & 0 & 0 & 0 & 0.03 & 0.97 \\
X_{16-2} & 0 & 0 & 0.04 & 0.81 & 0.15 \\
X_{16-3} & 0 & 0 & 0.78 & 0.21 & 0.01 \\
X_{2-1} & 0 & 0 & 0 & 0.11 & 0.89 \\
X_{2-2} & 0 & 0 & 0.06 & 0.89 & 0.05 \\
X_{3-1} & 0.45 & 0.53 & 0.02 & 0 & 0 \\
X_{3-2} & 0.88 & 0.12 & 0 & 0 & 0 \\
X_{3-5} & 0 & 0.54 & 0.45 & 0.01 & 0 \\
X_{3-6} & 0 & 0.51 & 0.46 & 0.03 & 0 \\
X_{4-1} & 0.59 & 0.37 & 0.04 & 0 & 0 \\
X_{4-2} & 0.37 & 0.63 & 0 & 0 & 0 \\
X_{4-3} & 0.60 & 0.39 & 0.01 & 0 & 0
\end{array}\right\}
$$

The data samples are normalized by using (18)-(19). In addition, the basic probability distribution matrix and formula obtained by using (12)-(13) are used to calculate the distance $D$ between the indicators and their similarity $S$. For example, the UCS (influencing factor $\mathrm{X}_{1-4}$ ) has a value of $105 \mathrm{MPa}$, whereas the initial geo-stress (influencing factor $\mathrm{X}_{1-5}$ ) has a value of $20.49 \mathrm{MPa}$. According to the theory of the cloud model and the generated cloud droplet map, the degree of certainty between the two different risk levels can be calculated separately. The UCS evaluation indicator belongs to the 2 nd and 3rd levels, with relative importance of 0.60 and 

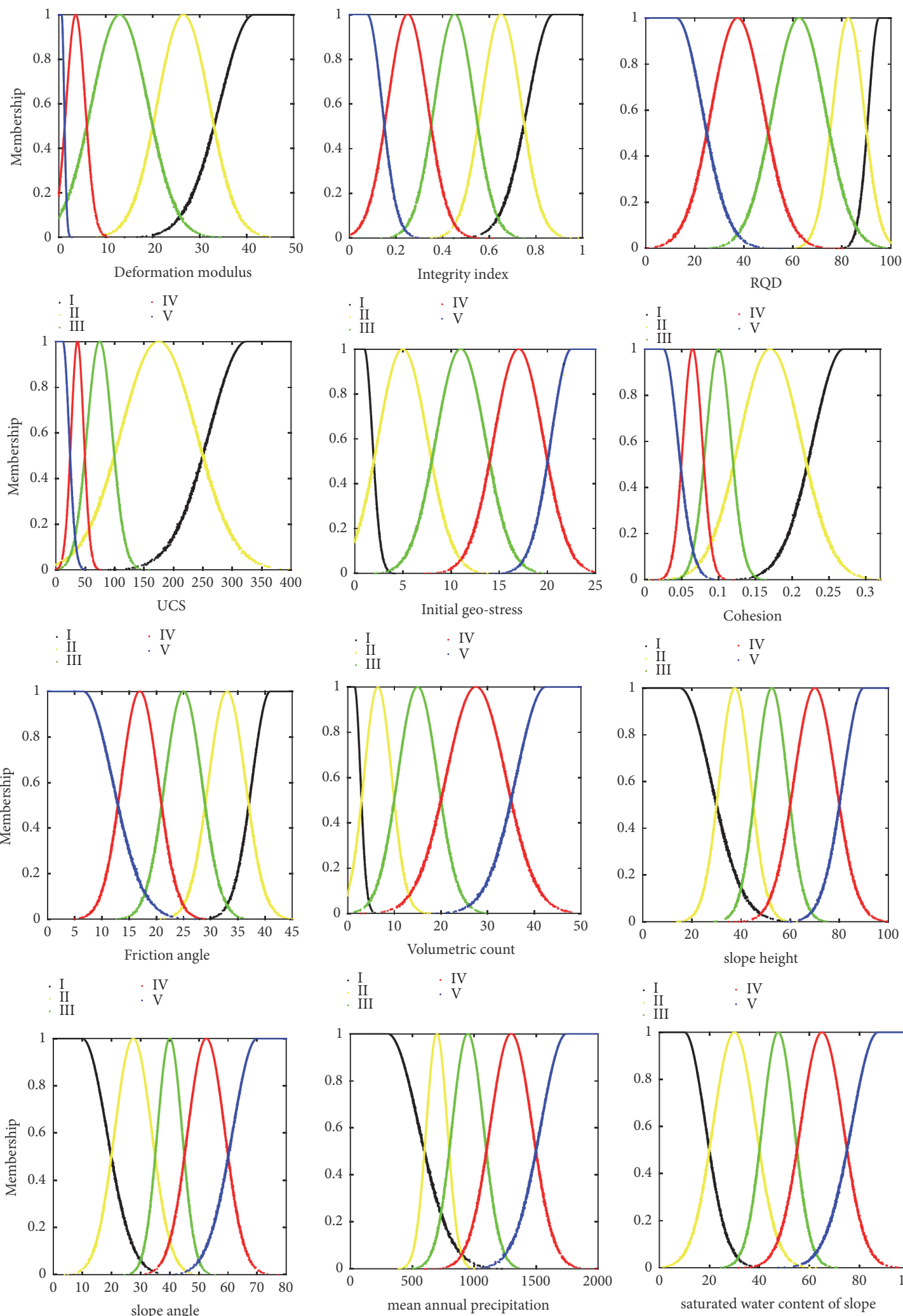

$\begin{array}{ll}\text { II } & \text { IV } \\ \text { III } & \text { V V }\end{array}$

II

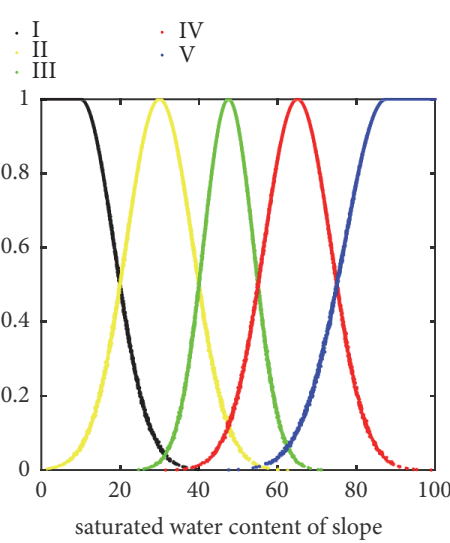

$\begin{array}{ll}\text { II } & \text { IV } \\ \text { III } & \text { V }\end{array}$

Figure 4: Continued. 

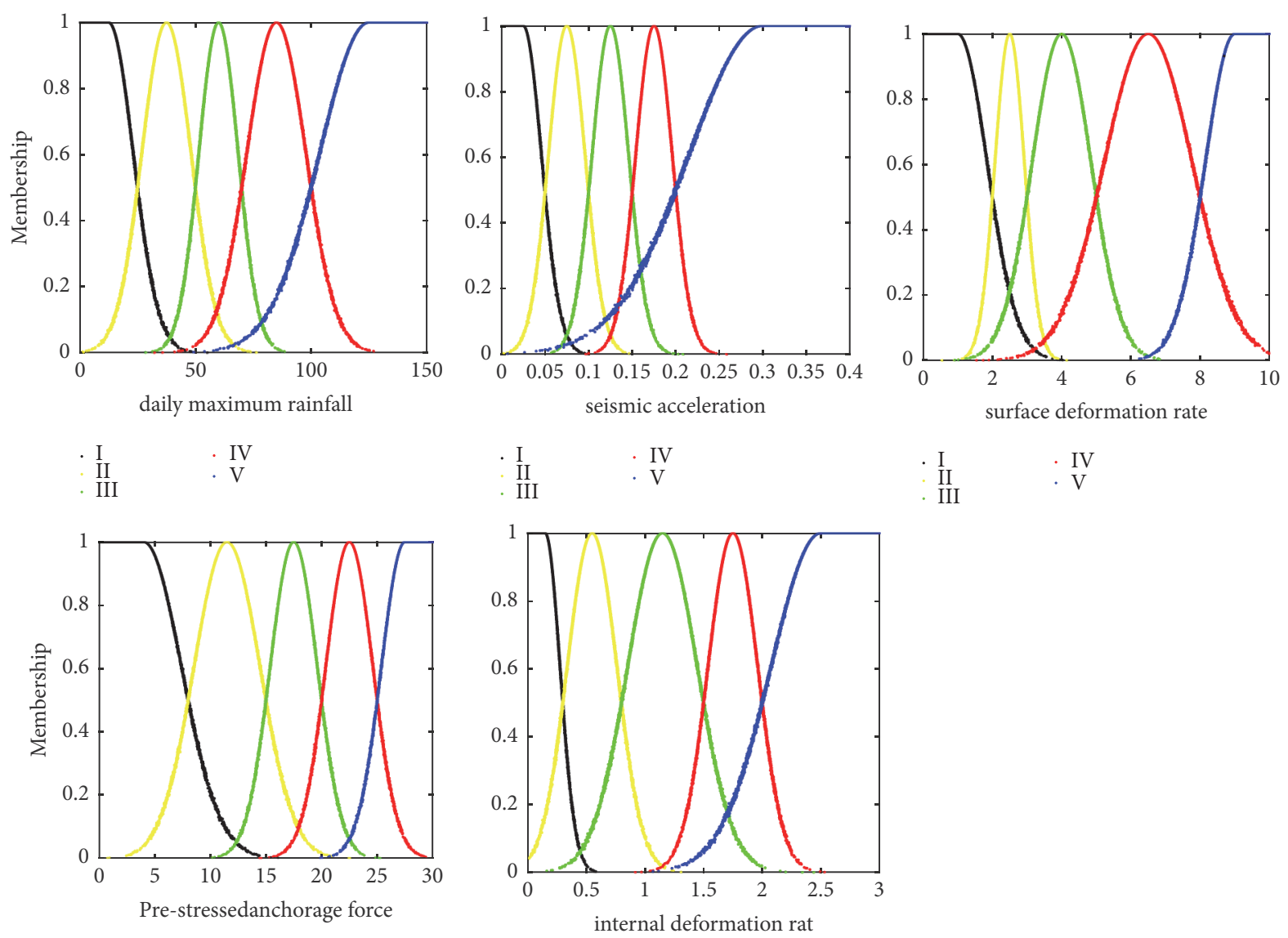

$\begin{array}{ll}\text { II } & \text { IV } \\ \text { III } & \cdot \text { V }\end{array}$

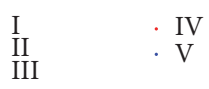

FIGURE 4: Generation of the cloud droplet graph.

0.40 , respectively. The initial geo-stress evaluation indicator belongs to the 4 th and 5 th hazard levels, with degrees of certainty of 0.19 and 0.81 , respectively. According to (12)(13), the distance and similarity between these two evaluation factors can be calculated as $D\left(X_{1-4}, X_{1-5}\right)=0.606$ and $S\left(X_{1-4}\right.$, $\left.X_{1-5}\right)=0.394$, respectively. The same approach can be used to calculate the distances and similarities between the remaining indicators in addition to the normalized measured values of the indicators. The specific results are reported in Table 4.

According to the calculation results presented in Table 4, by summing the similarities $E_{i}$ between a certain evaluation indicator $S\left(E_{\mathrm{i}}, E_{\mathrm{j}}\right)$ and all of the other indicators and then obtaining the support degree of the index, the same approach can be used to obtain the support degrees of the remaining evaluation indicators according to the calculated results. The weight formula (15) can provide the support degrees of all evaluation indicators. The weights of the final evaluation factors are listed in Table 4.

4.5. Final Classification Level Determination. According to the cloud model, Table 2 can be used to derive the threshold values of different evaluation indicators belonging to different hazard levels. The characteristic parameters of each level can be obtained using (2)-(4), and the measured values of the forward cloud model generator and of different evaluation factors are calculated accordingly. The sample data belong to different degrees of certainty; thus, the comprehensive certainty can be obtained by calculating the final certainty of the evaluation object according to the principle of maximum membership in (17). The calculation process is illustrated by taking evaluation factor $\mathrm{X}_{3-1}$ as an example. According to the cloud model, the degrees of certainty that $\mathrm{X}_{3-1}$ belongs to different hazard levels are $\mu_{1}=0.45, \mu_{2}=0.53, \mu_{3}=0.02$, and $\mu_{4}=\mu_{5}=0$. From this evaluation factor, we can speculate that the degree of certainty that the sample data belong to the first level of danger is 0.45 , the degree of certainty that the data belong to the second level is 0.53 , the degree of certainty that the data belong to the third level is 0.02 , and the degrees of certainty that the data belong to the fourth and fifth levels are 0 . According to this one indicator, the sample data most likely belong to the second level of danger; however, the data may belong to the first level, and there is a small possibility that the data belong to the third level. Additionally, it is impossible that the data belong to the 4th or 5 th level. Based on the attributes of the other indicators, the final samples belong to specific certainty degrees; ultimately, 


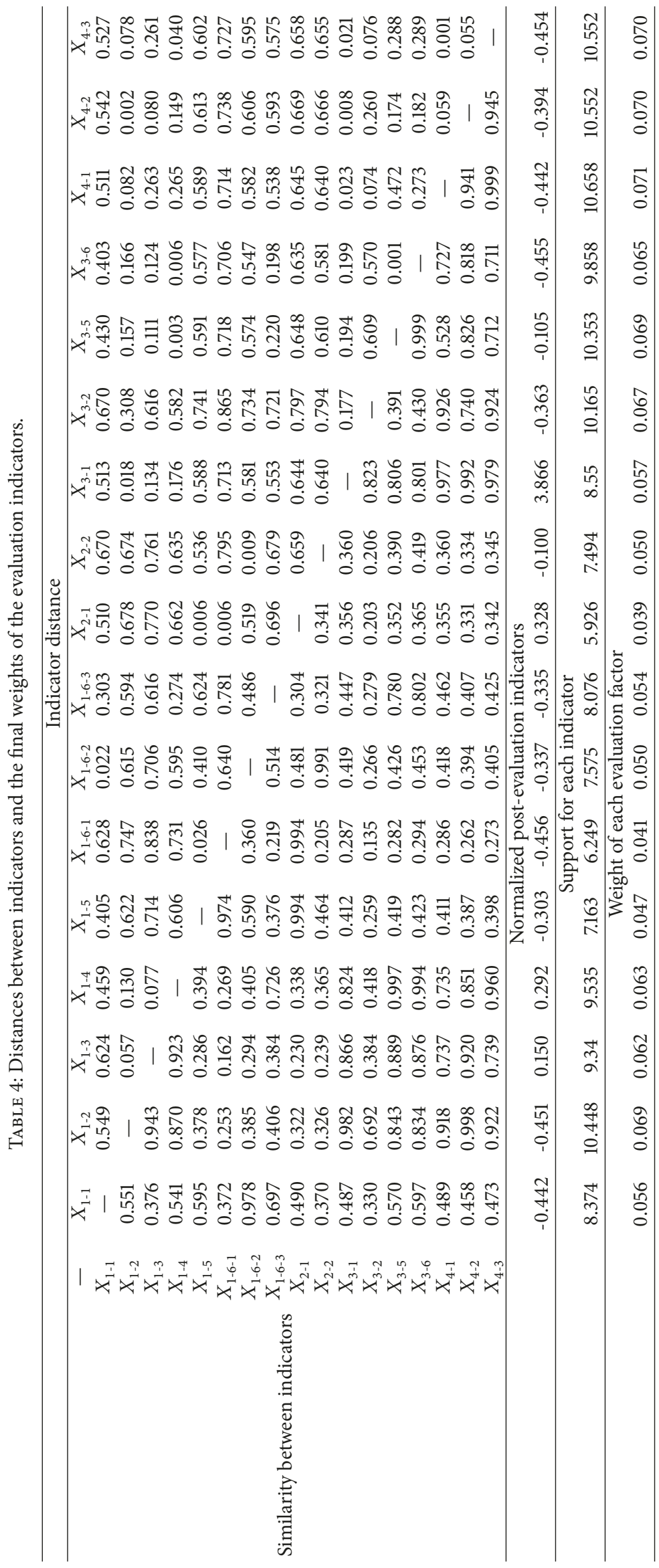


TABLE 5: The final weights belonging to different hazard levels.

\begin{tabular}{lccccc}
\hline \multicolumn{5}{c}{ Comprehensive certainty } & \multirow{2}{*}{ Final rating } \\
$\mu_{1}$ & $\mu_{2}$ & $\mu_{3}$ & $\mu_{4}$ & $\mu_{5}$ & \\
\hline 0.2196 & 0.3429 & 0.1535 & 0.1528 & 0.1297 & II \\
\hline
\end{tabular}

the comprehensive evaluation determines the risk of the evaluation object. According to the maximum membership principle based on the comprehensive membership degree in (16) in combination with the weight of each indicator obtained by the weighted distance discriminant method and the degrees of certainty of the evaluation factors, the final slope stability of the Jinping 1 Hydropower Station can be evaluated and rated. The final weights belonging to the different hazard levels are reported in Table 5.

According to the maximum membership principle, the certainty of the sample data belonging to the second level is 0.343 , and the degree of certainty belonging to the first level is 0.22 , whereas the final membership degrees of the other three levels are relatively small. Therefore, the final judgment is rated as the second level. Based on the final evaluation results and the actual construction conditions of the specific project, we can conclude that the improved cloud model with the weighted distance discriminant method is effective. Therefore, this mathematical method can be applied to the slope stability analysis of various engineering applications. This approach also provides new methods and ideas for similar issues.

In this paper, the distance discriminant method is used to obtain the weight. Compared with other weighting methods, the degree of mutual influence between each level of each index can be comprehensively considered, such that the determined weight is more reasonable and the accuracy of the evaluation method is improved. According to the measured value of the index, the weight of the index is obtained, which avoids the subjectivity of the traditional empowerment and the risk of being separated from the actual.

At the same time, the relationship between the indicators, the standard levels of the indicators, and the distributions of the indicators are considered, which avoids the defects that are easy to be partial in the process of empowerment.

Since the slope stability is a qualitative concept, the classification of its hazard level will be affected and controlled by many uncertain factors. The finite cloud generator is used to convert its ambiguity and randomness into the certainty degree, which reveals the evaluation process. The method of improving the feature parameters reduces the error of the calculation result to a certain extent, but it still cannot completely eliminate the gray feature of its existence. In addition, the actual distribution form of the slope stability evaluation index will have an impact on the evaluation results. The cloud model generated by the combination of the uniform distribution and the normal distribution reflects the actual situation more reasonably. Therefore, it is necessary to further improve the parameter method to make the result more accurate. Third, the evaluation factor should also be selected according to the actual project conditions, and it cannot be done overnight, because the influence factors of different types of slope engineering will be slightly different.

\section{Conclusions}

(1) This paper uses the weighted distance discriminant algorithm to calculate the weights of evaluation factors and selects the arch dam slope of the Jinping 1 Hydropower Station in Sichuan, China, as the research background. The degrees of influence of various evaluation index factors are comprehensively considered, and the accuracy of the evaluation index weights is improved. According to an analysis of the final evaluation results, the proposed algorithm can be employed not only to evaluate the safety of a slope but also to reveal the tendency of the risk of the sample to be evaluated and to obtain a prediction of the safety.

(2) According to the uncertainties in slope stability analysis, four evaluation indexes and 17 index factors (evaluation indicators) affecting slope stability are selected to make the evaluation results more reasonable. Moreover, the evaluation index system improves the credibility of the evaluation. At the same time, the method can also be applied to the safety evaluation of other hydraulic structures. For the slope stability analysis of other engineering types, the evaluation factors should also be selected according to their different natures.

(3) According to the traditional normal cloud model, the improved finite-area cloud model utilized in this paper can make the probability of membership of the evaluation index system more reasonable and accurate, thereby compensating for the fact that the theoretical distribution does not conform with the actual distribution and eliminates the possibility that the simulation results in the theoretical model may exceed the actual range of risk. At the same time, in combination with the weighted distance discriminant algorithm, the simulation results are more consistent with the actual situation. Combined with a variety of analysis methods, the prediction results of this method are relatively accurate and provide a feasible quantitative analysis method for engineering slope stability analysis.

(4) The safety evaluation model of rock slope stability based on the combination of an improved cloud model and a distance discriminant weighting method is based on multiangles and multifactors. The types and quantities of selected parameters are not limited, avoiding the onesidedness and subjective decision-making of single-factor decision-making. This model can be applied to the specific characteristics of different rock mass engineering and can accurately and scientifically predict the safety status of rock slope engineering. It has good applicability in both the construction and operation phases. Using this method, a safety preevaluation of the slope construction project can be achieved; before the project is constructed, the basic data of the evaluation factors affecting the slope stability can be collected to judge its stability, and then the feasibility of the project can be determined. It also provides a relatively reliable method for the preassessment of other projects. 


\section{Data Availability}

The [DATA TYPE] data used to support the findings of this study have been deposited in the Comprehensive Stability Evaluation of Rock Slope Using the Cloud Model-Based Approach repository (DOI: 10.1007/s00603-013- 0507-3).

\section{Conflicts of Interest}

The authors declare that they have no conflicts of interest.

\section{References}

[1] W. Yu, H. Zhang, P. Yang et al., "Risk assessment of highway slope disasters in loess areas based on cloud model," The Chinese Journal of Geological Hazard and Control, vol. 26, no. 4, pp. 111115, 2015.

[2] C. Yin, W. Tian, and J. Li, "Geological hazard investigation and risk assessment along the cat slope of Yonglan expressway," The Chinese Journal of Geological Hazard and Control, vol. 26, no. 3, pp. 127-132, 2015.

[3] D. Fereidooni, G. R. Khanlari, and M. Heidari, "Assessment of a modified rock mass classification system for rock slope stability analysis in the Q-system," Earth Sciences Research Journal, vol. 19, no. 2, pp. 147-152, 2015.

[4] M. S. Brook and E. Hutchinson, "Application of rock mass classification techniques to weak rock masses: A case study from the Ruahine Range, North Island, New Zealand," Canadian Geotechnical Journal, vol. 45, no. 6, pp. 800-811, 2008.

[5] S. Salween, K. A. Mohd Nayan, and M. O. Faruk Murad, "Evaluation on the stability of slope at faculty of engineering and built environment (FKAB) using slope/w," Jurnal Kejuruteraan, vol. 45, no. 6, pp. 79-86, 2016.

[6] Z. Liu, J. Shao, W. Xu, and F. Xu, "Comprehensive stability evaluation of rock slope using the cloud model-based approach," Rock Mechanics and Rock Engineering, vol. 47, no. 6, pp. 22392252, 2013.

[7] P. A. Cundall, "Formulation of a three-dimensional distinct element model-Part I. A Scheme to detect and represent contacts in a system composed of many polyhedral blocks," International Journal of Rock Mechanics and Mining Sciences \& Geomechanics Abstracts, vol. 25, no. 3, pp. 107-116, 1988.

[8] F. Jin, "Research status and prospects of slope stability analysis methods," West-China Exploration Engineering, vol. 4, pp. 5-9, 2007.

[9] A. Johari and A. Mehrabani Lari, "System probabilistic model of rock slope stability considering correlated failure modes," Computers \& Geosciences, vol. 81, pp. 26-38, 2017.

[10] W. Chen and P. Chen, "PSO slope: A Stand-Alone windows application for graphical analysis of slope stability," Advances in Swarm Intelligence, vol. 6728, pp. 56-63, 2011.

[11] M. Curtaz, A. M. Ferrero, R. Roncella, A. Segalini, and G. Umili, "Terrestrial photogrammetry and numerical modelling for the stability analysis of rock slopes in high mountain areas: Aiguilles marbrées case," Rock Mechanics and Rock Engineering, vol. 47, no. 2, pp. 605-620, 2014.

[12] D. Stead, E. Eberhardt, and J. S. Coggan, "Developments in the characterization of complex rock slope deformation and failure using numerical modelling techniques," Engineering Geology, vol. 83, no. 1-3, pp. 217-235, 2006.
[13] E. Eberhardt, D. Stead, and J. S. Coggan, "Numerical analysis of initiation and progressive failure in natural rock slopes-the 1991 Randa rockslide," International Journal of Rock Mechanics and Mining Sciences, vol. 41, no. 1, pp. 69-87, 2004.

[14] L. C. Li, C. A. Tang, W. C. Zhu, and Z. Z. Liang, "Numerical analysis of slope stability based on the gravity increase method," Computers \& Geosciences, vol. 36, no. 7, pp. 1246-1258, 2009.

[15] Z. Liu, W. Xu, and J. Shao, "Gauss process based approach for application on landslide displacement analysis and prediction," CMES: Computer Modeling in Engineering \& Sciences, vol. 84, no. 2, pp. 99-122, 2012.

[16] A. I. Husein Malkawi, W. F. Hassan, and F. A. Abdulla, "Uncertainty and reliability analysis applied to slope stability," Structural Safety, vol. 22, no. 2, pp. 161-187, 2000.

[17] J. T. Christian, C. C. Ladd, and G. B. Baecher, "Reliability applied to slope stability analysis," Journal of Geotechnical Engineering, vol. 120, no. 12, pp. 2180-2207, 1994.

[18] B. K. Low, R. B. Gilbert, and S. G. Wright, "Slope reliability analysis using generalized method of slices," Journal of Geotechnical and Geoenvironmental Engineering, vol. 124, no. 4, pp. 350-362, 1998.

[19] G. R. Dodagoudar and G. Venkatachalam, "Reliability analysis of slopes using fuzzy sets theory," Computers \& Geosciences, vol. 27, no. 2, pp. 101-115, 2000.

[20] H. J. Park, J.-G. Um, I. Woo, and J. W. Kim, "Application of fuzzy set theory to evaluate the probability of failure in rock slopes," Engineering Geology, vol. 125, pp. 92-101, 2012.

[21] A. Daftaribesheli, M. Ataei, and F. Sereshki, "Assessment of rock slope stability using the fuzzy slope mass rating (FSMR) system," Applied Soft Computing, vol. 11, no. 8, pp. 4465-4473, 2011.

[22] P. Lu and M. S. Rosenbaum, "Artificial neural networks and grey systems for the prediction of slope stability," Natural Hazards, vol. 30, no. 3, pp. 383-398, 2003.

[23] H. B. Wang, W. Y. Xu, and R. C. Xu, "Slope stability evaluation using back propagation neural networks," Engineering Geology, vol. 80, no. 3-4, pp. 302-315, 2005.

[24] M. G. Sakellariou and M. D. Ferentinou, "A study of slope stability prediction using neural networks," Geotechnical and Geological Engineering, vol. 23, no. 4, pp. 419-445, 2005.

[25] A. R. Zolfaghari, A. C. Heath, and P. F. McCombie, "Simple genetic algorithm search for critical non-circular failure surface in slope stability analysis," Computers \& Geosciences, vol. 32, no. 3, pp. 139-152, 2005.

[26] P. McCombie and P. Wilkinson, "The use of the simple genetic algorithm in finding the critical factor of safety in slope stability analysis," Computers \& Geosciences, vol. 29, no. 8, pp. 699-714, 2002.

[27] X. Wang, Q. Kang, J. Qin, Q. Zhang, and S. Wang, "Application of AHP-extenics model to safety evaluation of rock slope stability," Journal of Central South University (Science and Technology), vol. 44, no. 6, pp. 2455-2462, 2013.

[28] S. Song, Q. Wang, Y. Pan et al., "Evaluation of landslide susceptibility degree based on catastrophe theory," Rock and Soil Mechanics, vol. 35, pp. 422-428, 2014.

[29] Q. Huang, F. Fei, F. Xu et al., "Assessment research on the stability of rock mass slope based on matter-element model," Chinese Journal of Underground Space and Engineering, vol. 8, pp. 439-444, 2012.

[30] X. Dai, B. Zhang, and Z. Yan, "Application of finite cloud model and distance discrimination in slope stability evaluation," Journal of Railway Science and Engineering, vol. 15, pp. 71-78, 2018. 
[31] C. Yan, "Rough set distance discriminant analysis model of slope stability prediction and its application," Journal of Engineering Geology, vol. 24, pp. 204-209, 2015.

[32] J. Zhang, Z. Chen, and D. Liu, "Research on stability evaluation of rock slope based on cloud model," Hydrogeology and Engineering Geology, vol. 41, pp. 44-49, 2014.

[33] F. Yan, K. Xu, Z. Cui, and X. Yao, "An improved layer of protection analysis based on a cloud model: Methodology and case study," Journal of Loss Prevention in the Process Industries, vol. 48, pp. 41-47, 2017.

[34] J. Zhao and Y. Song, "Application of improved entropy weight normal cloud model in slope stability evaluation," Water Resources and Power, vol. 34, pp. 120-122, 2016.

[35] D. Li, H. Meng, and X. Shi, "Affiliated cloud and affiliated cloud generator," Computer Research and Development, vol. 32, pp. 1520, 1995.

[36] D. Li, H. Chen, J. Fan, and C. Shen, "A novel qualitative control method to inverted pendulum systems," IFAC Proceedings Volumes, vol. 32, no. 2, pp. 1495-1500, 1999.

[37] Z. Liu, J. Shao, W. Xu, and Y. Meng, "Prediction of rock burst classification using the technique of cloud models with attribution weight," Natural Hazards, vol. 68, no. 2, pp. 549-568, 2013.

[38] K.-P. Zhou, Y. Lin, H.-W. Deng, J.-L. Li, and C.-J. Liu, "Prediction of rock burst classification using cloud model with entropy weight," Transactions of Nonferrous Metals Society of China, vol. 26, no. 7, pp. 1995-2002, 2016.

[39] R. Mou and Q. Cai, "Research on classification method of surrounding rock stability based on cloud model and rough set theory," Journal of Safety and Environment, vol. 18, pp. 1251-1257, 2018.

[40] F. Khedim, N. Labraoui, and A. A. Abba Ari, "A cognitive chronometry strategy associated with a revised cloud model to deal with the dishonest recommendations attacks in wireless sensor networks," Journal of Network and Computer Applications, vol. 123, pp. 42-56, 2018.

[41] Y. Bao, L. Lin, S. Wu, K. A. Kwal Deng, and G. P. Petropoulos, "Surface soil moisture retrievals over partially vegetated areas from the synergy of Sentinel-1 and Landsat 8 data using a modified water-cloud model," International Journal of Applied Earth Observation and Geoinformation, vol. 72, pp. 76-85, 2018.

[42] D. Wang, D. Liu, H. Ding et al., "A cloud model-based approach for water quality assessment," Environmental Research, vol. 148, pp. 24-35, 2016.

[43] D. S. Efremenko, O. Schüssler, A. Doicu, and D. Loyola, "A stochastic cloud model for cloud and ozone retrievals from UV measurements," Journal of Quantitative Spectroscopy \& Radiative Transfer, vol. 184, pp. 167-179, 2016.

[44] M. Zhu, A. Hahn, and Y. Wen, "Identification-based controller design using cloud model for course-keeping of ships in waves," Engineering Applications of Artificial Intelligence, vol. 75, pp. 2235, 2018.

[45] W. Zang, L. Ren, W. Zhang, and X. Liu, "A cloud model based DNA genetic algorithm for numerical optimization problems," Future Generation Computer Systems, vol. 81, pp. 465-477, 2018.

[46] C. Li, X. Zhang, H. Geng, and J. Yan, "Robustness analysis model for madm methods based on cloud model," Procedia Computer Science, vol. 107, pp. 84-90.

[47] H. Gao, G. Xie, H. Liu et al., "Lateral control of autonomous vehicles based on learning driver behaviour via cloud model," The Journal of China Universities of Posts and Telecommunications, vol. 24, pp. 10-17, 2017.
[48] F. Q. Gong and X. B. Li, "Application of distance discriminant analysis method to classification of engineering quality of rock masses," Chinese Journal of Rock Mechanics and Engineering, vol. 26, no. 1, pp. 190-194, 2007 (Chinese).

[49] J.-H. Liu, T. Feng, W.-J. Wang, and D.-H. Xie, "Distance discriminant analysis method for distinguishing the difficulty degree of top-coal caving in steep seam and its application," Journal of the China Coal Society, vol. 33, no. 6, pp. 601-605, 2008.

[50] D. Li and Y. Du, Artificial Intelligence with Uncertainty, National Defense Industry Press, Beijing, China, 2nd edition, 2017.

[51] M. Wang, Q. Zhu, N. Zhu et al., "Evaluation of expansion and contraction of expansive soil and improved soil based on asymmetric contact cloud," Journal of Basic Science and Engineering, vol. 25, pp. 162-170, 2017.

[52] D. Li, C. Liu, and W. Gan, "A new cognitive model: cloud model," International Journal of Intelligent Systems, vol. 24, no. 3, pp. 357-375, 2009.

[53] R. del Potro and M. Hürlimann, "Geotechnical classification and characterization of materials for stability analyses of large volcanic slopes," Engineering Geology, vol. 98, no. 1-2, pp. 1-17, 2008.

[54] L. Pantelidis, "Rock slope stability assessment through rock mass classification systems," International Journal of Rock Mechanics and Mining Sciences, vol. 46, no. 2, pp. 315-325, 2009.

[55] P. Samui, S. S. Roy, and V. E. Balas, Handbook of Neural Computation, Academic Press, Pittsburgh, Pa, USA, 2017.

[56] Y. Song, H. Xue, and X. Meng, "Evaluation method of slope stability based on the Qslope system and BQ method," Bulletin of Engineering Geology and the Environment, pp. 1-9, 2019.

[57] K. Baba, L. Bahi, L. Ouadif, and A. Akhssas, "Slope stability evaluations by limit equilibrium and finite element methods applied to a railway in the moroccan rif," Open Journal of Civil Engineering, vol. 02, no. 01, pp. 27-32, 2012.

[58] R. Tomás, J. Delgado, and J. B. Serón, "Modification of slope mass rating (SMR) by continuous functions," International Journal of Rock Mechanics \& Mining Sciences, vol. 44, pp. 10621069, 2007.

[59] Y.-C. Liu and C.-S. Chen, "A new approach for application of rock mass classification on rock slope stability assessment," Engineering Geology, vol. 89, no. 1-2, pp. 129-143, 2007.

[60] K. Wang, F. Xu, Z. Liu et al., "Slope stability evaluation based on PSO-PP," Chinese Journal of Geotechnical Engineering, vol. 33, no. 11, pp. 1708-1713, 2011.

[61] N. Krivulin and S. Sergeev, "Tropical implementation of the Analytical Hierarchy Process decision method," Fuzzy Sets and Systems, pp. 1-21, 2018.

[62] O. S. Vaidya and S. Kumar, "Analytic hierarchy process: an overview of applications," European Journal of Operational Research, vol. 169, no. 1, pp. 1-29, 2006.

[63] A. Delgado and I. Romero, "Environmental conflict analysis using an integrated grey clustering and entropy-weight method: A case study of a mining project in Peru," Environmental Modeling and Software, vol. 77, no. 2, pp. 108-121, 2016.

[64] X. Li, K. Wang, L. Liu et al., "Application of the entropy weight and TOPSIS method in safe evaluation of coal mines," Procedia Engineering, vol. 26, no. 4, pp. 2085-2091, 2011.

[65] Z. Pawlak, "Rough set approach to knowledge-based decision support," European Journal of Operational Research, vol. 99, no. 1, pp. 48-57, 1997. 
[66] J. Yao, P. Lingras, W. Wu, M. Szczuka, N. J. Cercone, and D. Ślezak, "Decision-Theoretic rough set models," International Conference on Rough Sets and Knowledge Technology, vol. 4481, pp. 1-12, 2007.

[67] Y. Feng, X. Li, and X. Li, "Comprehensive evaluation of railway safety based on entropy weight method and grey relational analysis," Journal of Safety and Environment, vol. 14, pp. 73-79, 2014.

[68] C. Hsu and C. Chen, "Applications of improved grey prediction model for power demand forecasting," Energy Conversion and Management, vol. 44, no. 14, pp. 2241-2249, 2003.

[69] F. E. Boran, S. Genç, M. Kurt, and D. Akay, "A multi-criteria intuitionistic fuzzy group decision making for supplier selection with TOPSIS method," Expert Systems with Applications, vol. 36, no. 8, pp. 11363-11368, 2009.

[70] L. Gong and C. Jin, "Fuzzy comprehensive evaluation for carrying capacity of regional water resources," Water Resources Management, vol. 23, no. 12, pp. 2505-2513, 2009.

[71] J. Deng, S. Li, and X. Li, "Monitoring and stability analysis of reservoir bank slope in southwest China," Chinese Journal of Underground Space and Engineering, vol. 14, pp. 461-470, 2018.

[72] S. W. Qi, F. Q. Wu, F. Z. Yan, and H. X. Lan, "Mechanism of deep cracks in the left bank slope of Jinping first stage hydropower station," Engineering Geology, vol. 73, no. 1-2, pp. 129-144, 2004. 


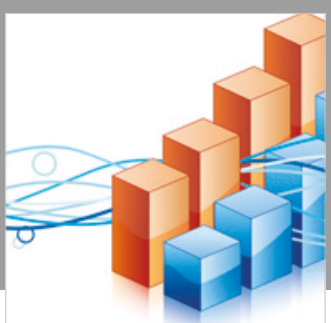

Advances in

Operations Research

\section{-n-m}
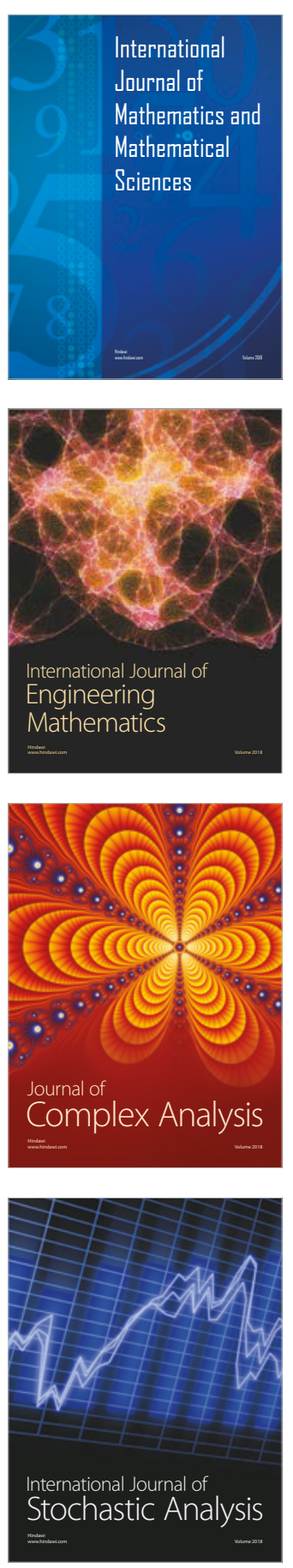
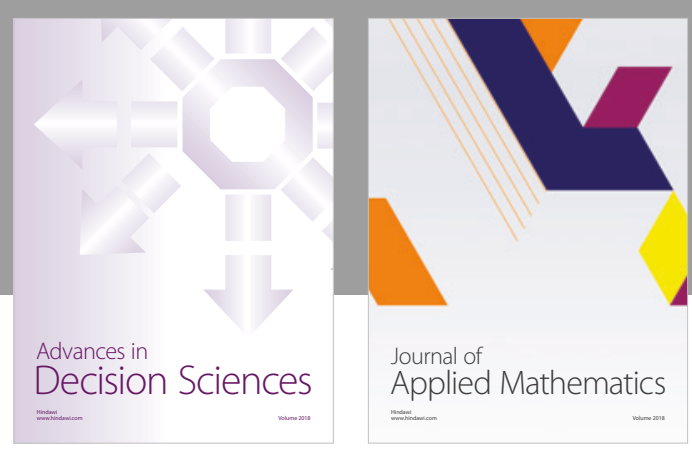

Journal of

Applied Mathematics
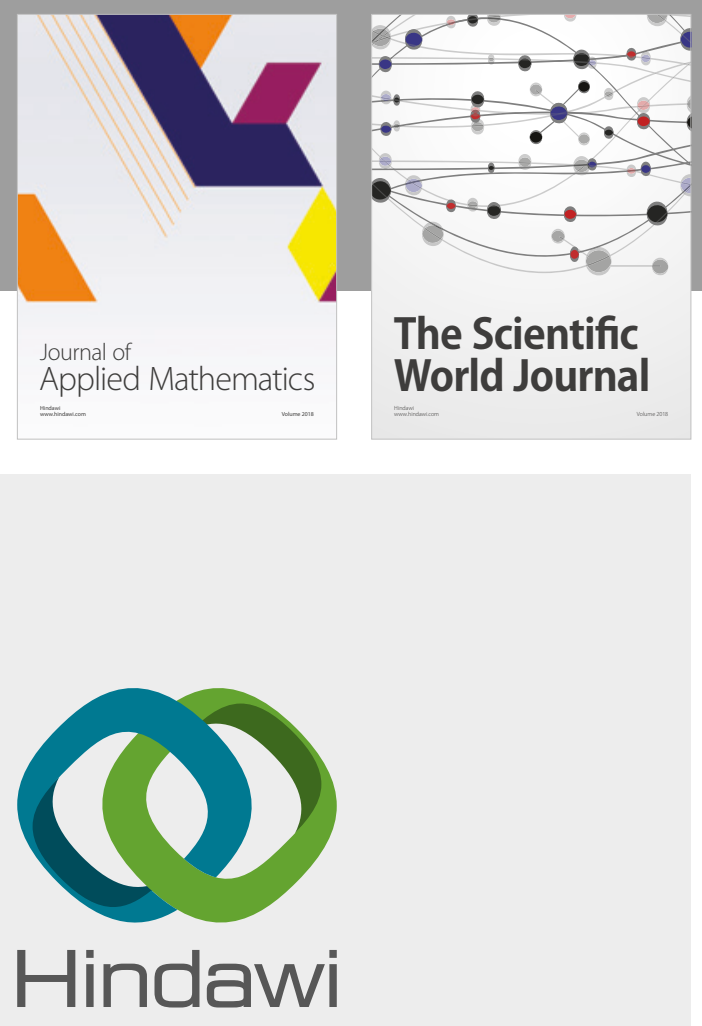

Submit your manuscripts at

www.hindawi.com

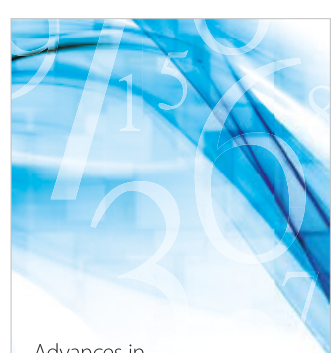

Advances in
Numerical Analysis
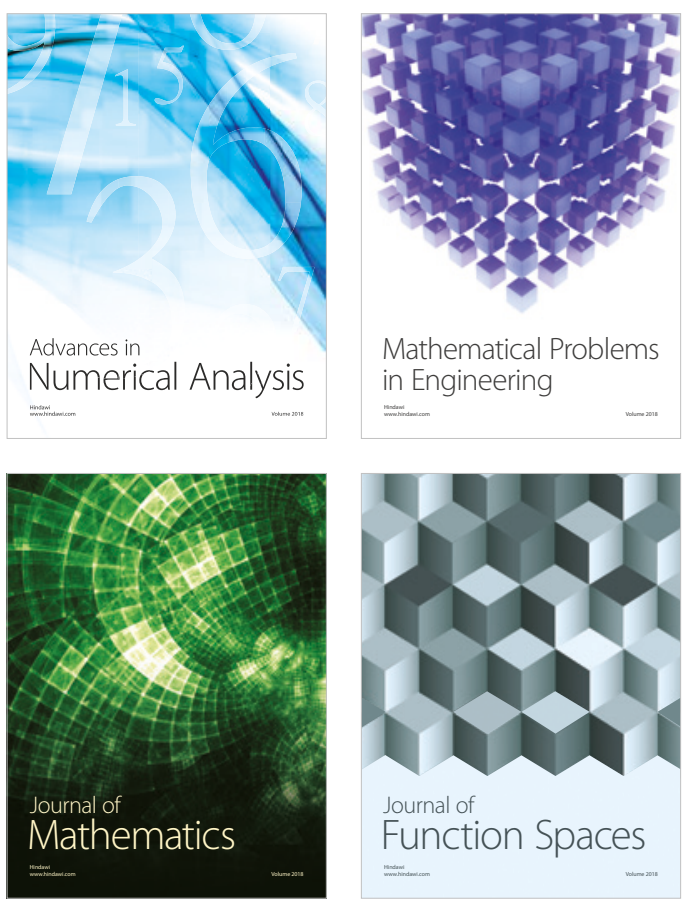

Mathematical Problems in Engineering

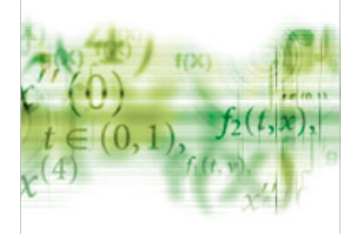

International Journal of

Differential Equations

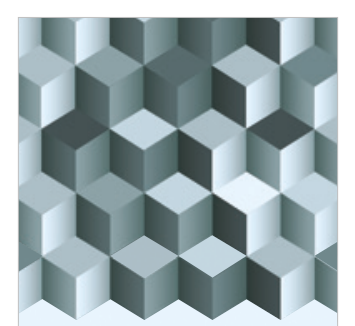

Journal of

Function Spaces

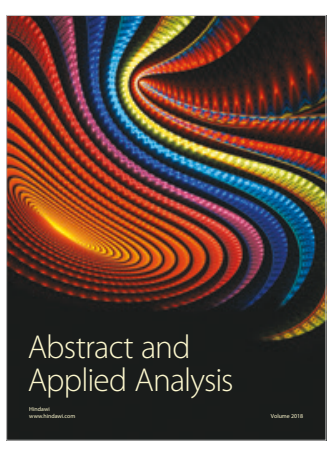

The Scientific

World Journal

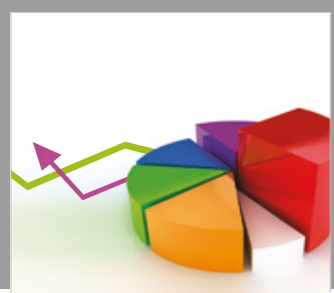

Journal of

Probability and Statistics
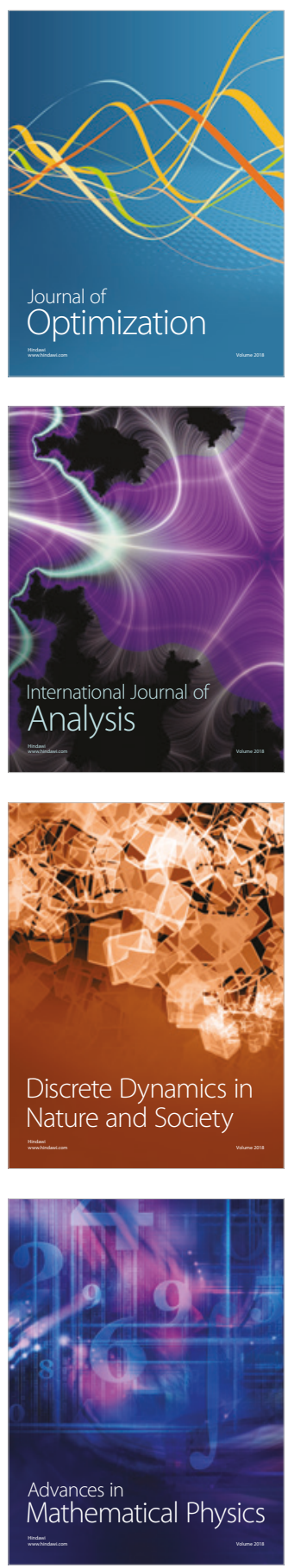